\title{
The use of telehealth in early autism training for parents: a scoping review
}

This article was published in the following Dove Press journal:

Smart Homecare Technology and TeleHealth

19 March 2014

Number of times this article has been viewed

\section{Michelle Boisvert' \\ Nerissa Hall ${ }^{2}$}

'WorldTide, Inc., Williamsburg, MA, USA; ${ }^{2}$ Communicare, LLC, Ludlow, MA, USA

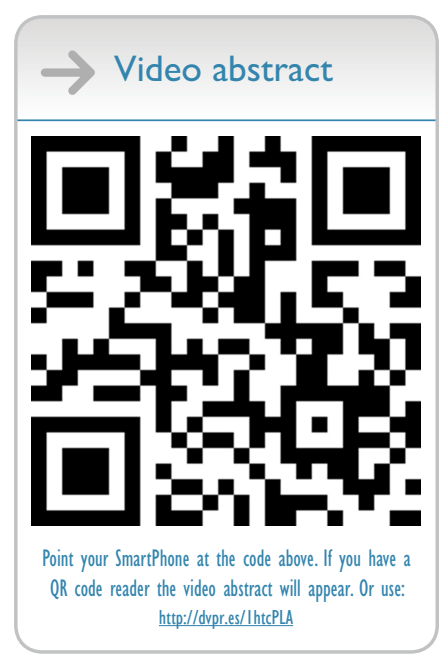

Correspondence: Michelle Boisvert WorldTide, Inc., PO Box 433 , Williamsburg, MA 01096-0433, USA Email michelleb@worldtide.com
Abstract: Telehealth involves the application of technology to deliver services over a geographical distance. Studies in which telehealth procedures were used in the training or coaching of parents with young children (aged 6 years and under) who were diagnosed with autism were reviewed. Scoping searches identified two studies that met the inclusion criteria. These studies were evaluated in terms of the: 1) characteristics of the participants; 2) technology utilized; 3) services delivered via telehealth; 4) research methodology; and 5) results and conclusions of the study. Telehealth was used by speech-language pathologists and university researchers to provide training to parents on specific intervention approaches to facilitate targeted communication initiations and responses by gestures, picture pointing, or verbalizations, as well as the delivery and evaluation of the Early Start Denver Model. While the available literature is limited on this topic, this review suggests that the use of telehealth is a viable means to provide training to parents with young children diagnosed with autism.

Keywords: autism spectrum disorder, telehealth, training, education, caregivers, parents

\section{Introduction}

Autism spectrum disorder (ASD) is a group of complex developmental disorders that impair an individual's ability to process and integrate ordinary information. ${ }^{1}$ The prevalence of ASDs is one out of every 88 children living in the United States, and there is a reported $78 \%$ increase in the diagnoses of autism today compared to a decade ago. ${ }^{2,3}$ Individuals with ASD exhibit difficulties in social interaction, communication, and attention; however, the severity of symptoms is different for each individual with the diagnosis. ${ }^{2}$ As the rate of autism increases, it places a major demand on families and specialists to secure and provide behavioral, educational, and family services. ${ }^{4}$

Given the nature of ASD, children with this diagnosis present with a variety of different clinical symptoms ranging from severe to minor impairments. This inherent heterogeneity complicates the clinical goal of identifying the predictors that are likely to affect a child's response to treatment. ${ }^{5}$ However, a large body of literature suggests that early interventions (EIs) are highly successful when provided at the age of diagnosis, with younger children yielding better outcomes. ${ }^{6-8}$ EI services are designed to promote development and improve the quality of life of young children aged from birth to six years, who have been identified as having a disability or developmental delay $^{2}$ such as autism. The goals of EI services are to enhance the capacity of families to help their child learn, achieve developmental milestones, and participate in home and community activities. ${ }^{9}$ Parental/caregiver involvement is vital to the long-term success of EI, as these individuals spend a significant amount of time with their 
child; they can support the generalizations of skills, and they can help create an everyday environment that fosters the implementation of such skills. Interventions provided by these individuals provide unique opportunities to maximize treatment outcomes. ${ }^{8}$

In most cases, specialized education is required to train caregivers in the necessary skills and strategies that enable them to become proficient agents of these interventions, and specialists need the opportunity to provide feedback or ongoing collaborative consultation with the parents about the implementation of various approaches. ${ }^{9,10}$ Ideally, the training should occur within the child's natural environment; however, this can be challenging given the intense one-on-one attention required from a highly qualified professional. ${ }^{10}$

Telehealth is a delivery model that uses telecommunications technology to provide therapeutic services at a distance. This enables individuals to receive professional services and support irrespective of their location. This may involve live video streaming to communicate in real time with a health care provider, or interacting with online multimedia platforms to learn new information. ${ }^{4,11}$ This method of service delivery for providing EI training to families has the potential to significantly improve the ability of providers to work with families in a timely manner, while delivering consultative services to the family in the child's naturalistic or home-based setting, and conducting professional development or training activities for parents and local professionals. ${ }^{9}$ To better understand how telehealth has been used for the training of caregivers as part of EI services for children with ASD, the authors conducted a scoping review to identify the extent and range of the existing literature on the use of telehealth for parental or caregiver training purposes, as well as to summarize the research findings. It was also the authors' intent to identify gaps in the research and to determine the future needs of study.

\section{Methods}

Published literature that addressed the use of telehealth technologies for the training and education of parents and caregivers with young children with ASD was identified through a careful search of seven major databases covering the field of health and human services (Education Resources Information Center [ERIC; Institute of Education Sciences, Washington, DC, USA], Academic Search Premier [EBSCO Industries, Inc., Ipswich MA, USA], PsycINFO ${ }^{\circledR}$ [American Psychological Association, Washington, DC, USA], PubMed [National Center for Biotechnology Information, US National Library of Medicine, Bethesda, MA, USA], CINAHL ${ }^{\circledR}$
[EBSCO Industries, Inc.], MEDLINE ${ }^{\circledR}$ [US National Library of Medicine, Bethesda, MA, USA], and WorldCat [OCLC, Dublin, $\mathrm{OH}, \mathrm{USA}]$ ) over a 2 -month period. Table 1 outlines the broad search terms that were used to identify key publications and literature.

The literature search was comprised of systematic steps that included a computer search using the keywords listed in Table 1 in the aforementioned databases. A sample search syntax for the first keywords in each term column would be "“autism' AND 'telehealth' AND 'parent training." Then, the abstracts of the identified articles were reviewed to ascertain compliance with the previously determined inclusion criteria listed in Table 2. If the article met the inclusion criteria, then full-text article retrieval was conducted. Reference lists of the included studies were then reviewed to identify additional articles for inclusion. The last name of the first author of each of the included studies was searched to identify supplementary work written by that author to be considered for inclusion in this review. Finally, hand searches of the two most current issues of the journals that had published at least one of the included studies were done in order to determine if recent studies were not yet listed in the aforementioned databases.

\section{Inclusion criteria}

To be included in this review, and in an effort to gain an understanding of the evidence pertaining to the use and application of telehealth as a method for delivering training services to parents with children diagnosed with autism, published studies had to meet predetermined inclusion criteria. The inclusion criteria for this review are outlined in Table 2. The search was limited to studies written in the English language and published in peer-reviewed journals. This literature review was conducted over the months of September 2013 and October 2013.

\section{Data extraction and review}

Each study was examined to determine whether or not it met the inclusion criteria. Then, each study was read and summarized by the authors of this review. Both authors hold

Table I Search terms and descriptors

\begin{tabular}{lll}
\hline Term I & Term 2 & Term 3 \\
\hline Autism & Telehealth & Parent training \\
Autism spectrum disorder & Telepractice & Parent education \\
Pervasive developmental & Teletherapy & Parent management \\
disorder & Telecare & \\
& Videoconference & \\
& Web conference & \\
\hline
\end{tabular}


Table 2 Inclusion criteria

\begin{tabular}{|c|c|}
\hline Criteria I & $\begin{array}{l}\text { The study had to include at least one participant } \\
\text { with a child diagnosed with autism between the ages } \\
\text { of } 0-6 \text { years. }\end{array}$ \\
\hline Criteria 2 & $\begin{array}{l}\text { At least one dependent variable focused on the skills } \\
\text { of the parent/caregiver, where the implementation of a } \\
\text { training, education, or management program supported } \\
\text { them and the child who had a diagnosis of autism. }\end{array}$ \\
\hline Criteria 3 & $\begin{array}{l}\text { The use of telehealth to deliver one of the above } \\
\text { services from a specialist or expert at one location } \\
\text { to a participant with a child with autism at a remote } \\
\text { location. }\end{array}$ \\
\hline
\end{tabular}

doctoral degrees in speech and hearing science, and are certified and licensed speech-language pathologists. The authors used a coding sheet designed specifically for this systematic review (available upon request) to extract data describing: 1) the characteristics of the participants;2) the type of support services delivered via telehealth; 3 ) the technology utilized to support the parental training program; 4) the uses and benefits of the training program; 5) the research design utilized; and 6) the results and conclusions of the study. Various procedural features were noted, including the settings of the telehealth training services and any reported advantages and disadvantages to implementation.

\section{Inter-coder agreement}

Each co-author independently completed the systemic literature review using the keywords listed in Table 1. The accuracy of each summary was independently checked to ensure that the studies adhered to the review criteria. This helped guarantee accuracy of each of the study summaries and provided a measure of inter-coder agreement on data extraction and analysis. The point-by-point inter-coder agreement was calculated by dividing the number of agreements by the total number of agreements and disagreements and multiplying by 100 .

\section{Results}

To ensure the fidelity of the literature search, each component of the aforementioned procedures was completed independently by the authors of this review. The first stage (the electronic database review of keyword combinations) yielded 13 studies. The abstracts of the 13 studies were reviewed to determine whether or not they met the inclusion criteria. Of these 13 articles, it was determined that only two of them adhered to the inclusion criteria and contained information about the outcomes of a training or management program for parents with young children with ASD. Inter-coder agreement regarding whether a study should be included or excluded was $100 \%$. While the number of articles analyzed in this review was low, it was to be expected, as a previous literature review conducted by Cason ${ }^{9}$ found only five studies pertaining to telehealth for EI for children with any type of diagnosis and service. In relation to this current review, Table 3 offers a summary of: 1) the participants; 2) the technology used; 3) the services delivered via telehealth; 4) the research design; and 5) the results of each of the two included studies.

\section{Included studies}

Two studies met the inclusion criteria for this review. ${ }^{4,11}$ One conducted a proof-of-concept pilot study in 2010 to determine the feasibility of using remote technology in parent training in EI for autism within a home setting. ${ }^{11}$ This research team compared two models of service delivery for two preschool-aged subjects with autism that specifically targeted strategies aimed at increasing the children's attention and motivation, turn-taking routines, initiating and responding to joint attention, communication, using pictures and objects, and imitation. This study set out to determine if: 1) a telehealth clinical model was as effective as a traditional clinical model to support parent and child behaviors designed to promote social and communication interaction; 2) if target behaviors achieved in a clinic setting could also be achieved in the home session; and 3) if overall progress in communication and social interactions could be maintained throughout the study period.

To evaluate these variables, this study had two phases: phase A and phase B. Phase A consisted of two intervention sessions that were conducted each week at a university clinic. In contrast, phase B consisted of two intervention sessions that were conducted each week, with one offered at a university clinic and the other offered in the child's home setting. Assessment measures were repeated at three points over the course of this study. The first measure was taken at the midpoint in study period $\mathrm{A}$, the second was taken at the baseline for study period $\mathrm{B}$, and the third measure was taken at the end of study period B. To assess each child's communication and socialization skills with respect to receptive and expressive language and social relations, the Vineland Adaptive Behavior Scale was used. ${ }^{12}$ To assess the children's development for words understood (WU), words produced (WP), and gestures (G), the MacArthur Communicative Development Inventories (CDI) was implemented. ${ }^{13} \mathrm{~A}$ video analysis of the child's clinical interactions was conducted to determine the number of child-initiated responses and the 
Table 3 Summary of the included studies

\begin{tabular}{|c|c|c|c|c|}
\hline Participants & Technology & Services & Design & Summary of outcomes \\
\hline \multicolumn{5}{|l|}{ Baharav and Reiser"I } \\
\hline $\begin{array}{l}\text { Two parent-child } \\
\text { dyads; children between } \\
\text { the ages of } 4-5 \text { years } \\
\text { old diagnosed with ASD }\end{array}$ & $\begin{array}{l}\text { Dell }^{\text {TM }} \text { Latitude }^{\text {TM }} 2100 \\
\text { Netbook; built-in webcam; } \\
\text { Bluetooth }{ }^{\circledR} \text { headset; } \\
\text { Skype; } \\
\text { Virtual portal }\end{array}$ & $\begin{array}{l}\text { SLP coached parents in a } \\
\text { home session targeting } \\
\text { intended communication } \\
\text { once each week }\end{array}$ & $\begin{array}{l}\text { Single-subject time } \\
\text { series (A-B) repeated } \\
\text { measures; parent } \\
\text { survey }\end{array}$ & $\begin{array}{l}\text { Child-initiated communication } \\
\text { increased } \\
\text { Adult overtures increased } \\
\text { Receptive and expressive } \\
\text { language and social relations gains } \\
\text { Mixed findings for words understood, } \\
\text { words produced, and gestures } \\
\text { Parents provided a larger number of } \\
\text { social engagement behaviors than did } \\
\text { the clinician } \\
\text { High level of parental satisfaction } \\
\text { Parents felt the services delivered via } \\
\text { telehealth at home were valuable } \\
\text { Some dissatisfaction with the wireless } \\
\text { headset }\end{array}$ \\
\hline
\end{tabular}

*Vismara et $\mathbf{a l}^{4}$

Eight parent-child dyads; children between

1.5-3.75 years of age

diagnosed with ASD

\author{
Laptop; desktop computer; \\ webcam; broadband \\ Internet; 128-bit encrypted \\ platform
}

Parents received 1.5 hours weekly of training on various intervention techniques from the Early Start Denver Model ${ }^{20}$
Multiple-baseline design; parent survey

Improvement of children's functional verbal utterances and nonverbal joint attention initiations

Increased production and comprehension of words and gestures Parents demonstrated gains in intervention skills

Parents demonstrated a gain in engagement toward their child Parents reported satisfaction with the website

Increased parental confidence

Notes: *Dr Vismara is an author of the parent curriculum used in this study and receives royalties from its sale. The manufacturer details for these products are as follows: Dell $^{T M}$ Latitude $^{T M} 2100$ Netbook (Dell Inc., Round Rock, TX, USA); Bluetooth ${ }^{\circledast}$ (Bluetooth SIG, Inc., Kirkland, WA, USA); and Skype version 4.0 (Skype, Luxembourg City, Luxembourg). (A-B) refers a two phase design consisting of a baseline phase (A) and an intervention phase (B).

Abbreviations: ASD, autism spectrum disorder; SLP, speech language pathologist.

opportunities clinicians and parents provided to the child for reciprocal social interactions. Finally, parental questionnaires were given to assess their overall satisfaction with the telehealth clinical intervention and coaching sessions.

The second study (Vismara et $\mathrm{al}^{4}$ ) reported on the preliminary findings of a parent training program using the Early Start Denver Model (P-ESDM) website. This study examined the use of a telehealth program that consisted of live videoconferencing in combination with a self-guided website to conduct parent training in the homes of eight families with young children with ASD. The aim of this research was to determine: 1) whether or not parents perceived the telehealth program as a useful learning platform for disseminating a training model; 2) whether parent intervention skills and engagement styles improved over time as a result of the telehealth program; 3 ) the parental activity on a self-guided website that assisted learning and use of the intervention strategies; and 4) if children's verbal language and joint attention initiations improved from a parent's implementation of target strategies. To assess these measures, video analysis and a series of standardized measures were implemented at three points throughout the study: at baseline; intervention; and follow-up.

Parent satisfaction and perception of the telehealth training program was assessed using the features built into the P-ESDM website. Parents were asked to complete an eightitem, five-point response scale to evaluate their satisfaction with the telehealth intervention at the end of the 12-week study. To determine the progression of parent intervention skills, the P-ESDM Fidelity Tool (University of California, Davis, MIND Institute, CA, USA) was utilized. This tool was a Likert-based 5-point rating system of 13 parent behaviors that define the child-centered responsive interactive style used in the P-ESDM. Scores ranged from one (ie, no competence) to five (ie, high competence). Scores of 4 or greater indicated that the skill was being correctly implemented with consistency in terms of the appropriate technique and use. The Maternal Behavior Rating Scale (MBRS) ${ }^{14}$ was used to 
determine the overall parental engagement style for this study. The MBRS is a five-point Likert rating scale with responses that ranged from 1 (very low) to 5 (very high) to assess a parent's responsiveness and sensitivity to their child's overt and subtle needs, enjoyment and warmth displayed during the interaction, adult-directedness and teaching pace, and goalachievement behaviors to target the child's developmental skills. The total MBRS scores included all subscales except directiveness, as this subscale uses the median rating, not the highest rating, to reflect the most optimal parenting style.

Child behaviors and their response to parents' use of the intervention were measured through behavioral scoring and parent reporting. Videotaped probes were transcribed and analyzed for the child's production of functional verbal utterances consisting of single words or approximations directed toward the adult. Nonverbal joint attention initiations that involved eye gaze alternations, with or without $\mathrm{G}$, elicited by the child without any prompting or encouragement from the parent, and directed to the parent for the purposes of sharing interest or enjoyment in an activity were also recorded. These weekly parent-child activities were recorded and independently rated by two research assistants, and then checked for reliability with the first author of this study. To examine the parent's perceptions of the child's improvement, as related to the observed changes, parents completed the MacArthur CDI ${ }^{13}$ at the three assessment points throughout the study.

\section{Participant characteristics}

Collectively, the two studies involved a total of ten participants. The studies assessed the outcomes of an intervention program in which the parents of young children with ASD were trained via telehealth to administer a specific intervention. One study included two parent-child dyads, ${ }^{11}$ and the other study involved eight parent-child dyads. ${ }^{4}$

Vismara et $\mathrm{al}^{4}$ reported that all eight of the parents in their study were married, and at least one parent had a college or post-college education. It was reported that the parents had an annual income of between US \$16,000 to over US \$100,000. Parents' marital status, sex, education level, and annual income were not reported in the other study. ${ }^{11}$ Of the two studies, both reported that all child participants met the Diagnostic and Statistical Manual of Mental Disorders, 4th Edition criteria for autism and were between the ages of 1.5-5 years.

\section{Technology used}

The two included studies utilized widely available technology such as laptop computers, Bluetooth headsets, videoconferencing systems and broadband Internet. Baharav and Reiser ${ }^{11}$ reported that the parents were given a DellTM Latitude $^{\text {TM }} 2100$ Netbook (Dell Inc., Round Rock, TX, USA) with a built-in webcam. They used a wireless Bluetooth ${ }^{\circledR}$ (Bluetooth SIG, Inc., Kirkland, WA, USA) headset for communication with the clinician during the training/coaching sessions. To observe the home session, the research team used the freeware program, Skype version 4.0 (Skype, Luxembourg City, Luxembourg). Moreover, an Internet portal was used to create a virtual meeting place for social networking and to exchange information between the clinician and parents. The treating clinician used a university clinic's lab computer for all videoconferencing contact.

Vismara et $\mathrm{al}^{4}$ reported that the families completed the telehealth intervention sessions using a laptop and webcam. The treating clinician used an office computer and webcam. The therapist and parents accessed a videoconferencing program that was a feature of the P-ESDM website via a 128-bit encrypted software platform. In this study, the parents accessed the ESDM self-guided website. It was reported that this website engaged the parents in the delivery and evaluation of the Early Start Denver Model (ESDM). ${ }^{20}$

\section{Services delivered}

The services delivered via telehealth included direct speech, language, and consultation services. The aim of these services was to target child communication initiations and responses by $\mathrm{G}$, picture pointing, or verbalizations, and to deliver and evaluate the ESDM.

Following the baseline, the researchers in the Baharav ${ }^{11}$ study provided speech and language services to two preschool-aged children over two consecutive treatment periods, a control period (period A) and an experimental period (period B), each lasting 6 weeks. The control period followed a traditional clinical model (two 50-minute sessions each week at a clinic) and the experimental period included one 50-minute session at the clinic and a second 50-minute session at home, offered by the parent who followed a prescribed lesson plan while being coached by a specialist in a remote location. Both $\mathrm{A}$ and $\mathrm{B}$ periods were similar in that the parent was present in the room, he or she observed the intervention that was provided, and was encouraged to interact with his or her child using specific strategies. However, during the home-session, in the experimental period, the parent was the primary interventionist and was monitored remotely and coached by the highly qualified clinician. The clinician coached and provided cues to the parent regarding proper implementation of the intervention strategies. 
Vismara et $\mathrm{a}^{4}$ worked with parents using the ESDM. The ESDM is a developmental, relationship-based intervention grounded in the science of applied behavior analysis for toddler and preschool-aged children with ASD. This research team utilized the parent model of the ESDM and its associated training program, which features text and video-based learning modules that include strategies; an introduction; rational, stepby-step instructions; checklist questions; and video examples for each topic that is being targeted. As part of this investigation, parent coaching sessions occurred once each week for approximately 1.5 hours for 12 weeks by the first author and one other qualified therapist. The two therapists would initiate the video call and, once connected, they would ask the parents to relay the events that occurred in the previous week in direct relation to the intervention topic. This would be followed by a 10-minute observation of the parent-child interaction, which served as an opportunity to collect data and gather weekly outcome measures. Coaching and suggestions were not given to the parent until after the 10-minute observation sessions were finished. Following this, the therapist and parent discussed the parent's experience in relation to the intervention topic, child's behaviors, and personal learning goals. Moreover, the therapist could also view the parents' activity with the P-ESDM website to view their usage and progress with the intervention and goals outside of the weekly sessions.

\section{Design of the research studies}

Both studies utilized a single-subject design to evaluate the efficacy of training services delivered via telehealth, and the progress toward skill acquisition demonstrated by each child. Baharav and Reiser ${ }^{11}$ implemented a single-subject, time series, repeated measures design, and Vismara et $\mathrm{al}^{4}$ used a multiple baseline design.

Table 4 Outcomes for child behaviors

\begin{tabular}{|c|c|c|c|c|c|c|}
\hline & \multicolumn{2}{|c|}{$\begin{array}{l}\text { Data point I } \\
\text { (midpoint for phase A) }\end{array}$} & \multicolumn{2}{|c|}{$\begin{array}{l}\text { Data point } 2 \\
\text { (baseline for phase B) }\end{array}$} & \multicolumn{2}{|c|}{$\begin{array}{l}\text { Data point } 3 \\
\text { (end of phase B) }\end{array}$} \\
\hline & Child I & Child 2 & Child I & Child 2 & Child I & Child 2 \\
\hline $\begin{array}{l}\text { Initiated communication } \\
\text { (frequency count) }\end{array}$ & 35 & 4 & 6 & 8 & 33 & 8 \\
\hline \multicolumn{6}{|l|}{ (reported as percentages) } & $72 \%$ \\
\hline Vineland Adaptive Behavior Scales & $\mathrm{RL}=6$ & $R L=21$ & $\mathrm{RL}=7$ & $\mathrm{RL}=25$ & $R L=I I$ & $\mathrm{RL}=28$ \\
\hline \multirow[t]{2}{*}{ (reported in raw scores) } & $E L=14$ & $E L=21$ & $E L=13$ & $E L=31$ & $E L=14$ & $E L=36$ \\
\hline & $S R=16$ & $S R=19$ & $S R=16$ & $S R=25$ & $S R=17$ & $S R=23$ \\
\hline MacArthur CDI & $W U=54$ & $\mathrm{WU}=44$ & $W U=47$ & $W U=221$ & $W U=278$ & $W U=311$ \\
\hline \multirow[t]{2}{*}{ (reported in raw scores) } & $\mathrm{WP}=0 *$ & $\mathrm{WP}=0 *$ & $\mathrm{WP}=0 *$ & $W P=37$ & $W P=95$ & $W P=103$ \\
\hline & $\mathrm{G}=23$ & $\mathrm{G}=20$ & $\mathrm{G}=22$ & $\mathrm{G}=33$ & $\mathrm{G}=4 \mathrm{I}$ & $\mathrm{G}=4 \mathrm{I}$ \\
\hline
\end{tabular}

Notes: *The WP subtest was not applicable for these participants, as it was reported that this child had mutism. Reproduced from Baharav and Reiser." Copyright @ 2010. The publisher for this copyrighted material is Mary Ann Liebert, Inc. publishers.

Abbreviations: CDI, Communicative Development Inventories; RL, receptive language; EL, expressive language; SR, social relations; WU, words understood; WP, words produced; G, gestures.

Both studies implemented a survey to the parents to determine their satisfaction with the use of technology, its ability to provide the targeted intervention, and their perceptions of their child's improvement over the course of the studies. Baharav and Reiser ${ }^{11}$ gave parents questionnaires at the end of the experimental period and asked them to assess their experience with the technology used in the telehealth sessions using a Likert scale to evaluate their experience as providers of EI services for their child. Vismara et $\mathrm{al}^{4}$ asked parents to complete the MacArthur CDI and the MBRS.

\section{Outcomes - child skills}

Both investigations included in this review confirmed the feasibility and parental satisfaction with the use of telehealth for the training of parents supporting their children with ASD in EI supports.

With respect to the overall development of child skills and behaviors, Baharav and Reiser ${ }^{11}$ reported that the number of times each subject initiated communication, responded to adult initiated overtures, and demonstrated an overall use of language increased over the course of the study. Responses to adult overtures were defined as following directions to act, or invitations to perform a routine. It was reported that both subjects increased the percentage of their responses for the home-based intervention session when assessed during the third data measurement. As seen in Table 4, this research team reported that the frequency of child-initiated communication within a clinical session increased across the three data measurement points. This is consistent with the findings from the Vismara et al study. ${ }^{4}$ As seen in Table 5, it was reported that the rates of children's functional verbal utterances and nonverbal joint attention initiations across baseline, during the intervention, and at follow-up resulted 
Table 5 Averaged outcomes for child behaviors

\begin{tabular}{llll}
\hline & $\begin{array}{l}\text { Data point I } \\
\text { (baseline) }\end{array}$ & $\begin{array}{l}\text { Data point 2 } \\
\text { (intervention) }\end{array}$ & $\begin{array}{l}\text { Data point 3 } \\
\text { (follow-up) }\end{array}$ \\
\hline Rate of vocalization (frequency count) & $2.97(\mathrm{SD}=1.83)$ & $3.60(\mathrm{SD}=2.5 \mathrm{I})$ & $4.14(\mathrm{SD}=2.04)$ \\
Rate of joint attention (frequency count) & $\mathrm{I} .67(\mathrm{SD}=1.07)$ & $1.67(\mathrm{SD}=1.2 \mathrm{I})$ & $2.16(\mathrm{SD}=1.34)$ \\
MacArthur CDI (reported in SS) & $\mathrm{VP}=11 \mathrm{I} .87(\mathrm{SD}=156.03)$ & $\mathrm{VP}=163.88(\mathrm{SD}=156.03)$ & $\mathrm{VP}=213.88(\mathrm{SD}=155.08)$ \\
& $\mathrm{C}=224.37(\mathrm{SD}=133.25)$ & $\mathrm{C}=284.88(\mathrm{SD}=141.53)$ & $\mathrm{C}=3 \mid 4.88(\mathrm{SD}=94.16)$ \\
\hline
\end{tabular}

Note: Data from Vismara et al. ${ }^{4}$

Abbreviations: SD, standard deviation; CDI, Communicative Development Inventories; SS, standard score; VP, vocabulary production; C, comprehension.

in an overall improvement, despite considerable variability from session to session.

Both studies reported on parental skills using the MacArthur CDI. Through this measurement, WU, WP, and $\mathrm{G}$ were assessed. Baharav and Reiser ${ }^{11}$ reported mixed results in that there were reduced scores for $\mathrm{WU}$ and $\mathrm{G}$ for one participant and a substantial growth in WU, WP, and G for the second. Vismara et al ${ }^{4}$ found that there was increased production and comprehension of words and $\mathrm{G}$ for all children from baseline to follow-up.

Baharav and Reiser ${ }^{11}$ also reported on the data collected from the Vineland Adaptive Behavior Scales to assess receptive language, expressive language, and social relations. Although this study was relatively short in duration, some gains were observed when comparing the observed data from the first measurement point to the third measurement point for both subjects, demonstrating a growth in language domain skills.

\section{Outcomes - parent skills}

The studies presented in this scoping review implemented measures to assess parental skills. Baharav and Reiser ${ }^{11}$ assessed parents' effectiveness in eliciting their children's social engagement behaviors by documenting the number of opportunities parents elicited such behaviors, as compared to the number of opportunities where clinicians elicited such behaviors during two 50-minutes sessions. Vismara et $\mathrm{al}^{4}$ used the P-ESDM and reported that parents demonstrated steady gains in intervention skills from baseline as compared to a follow-up performance. Results from the Baharav and Reiser ${ }^{11}$ study suggested that parents provided a larger number of social engagement behaviors than did the clinician, as seen in Table 6. Likewise, results from the Vismara et al ${ }^{4}$ study

Table 6 Clinician and parent elicitation of social engagement

\begin{tabular}{lll}
\hline Participant & Clinician & Parent \\
\hline Child I & 44 & 67 \\
Child 2 & 53 & 60 \\
\hline
\end{tabular}

Note: Reproduced from Baharav and Reiser." Copyright $\odot$ 2010. The publisher for this copyrighted material is Mary Ann Liebert, Inc. publishers. suggested that after 7 weeks of intervention training, parents achieved a satisfactory level of fidelity on implementing target skills (as seen in Table 7), and they also reported that parents' engagement toward their child improved across different phases of the study.

\section{Outcomes - parent satisfaction}

To assess parents' attitudes and perceptions of the effectiveness of using the telehealth technology, both research teams asked parents to fill out a questionnaire at the end of the study period. It was reported in both studies that parents felt equally comfortable using the technology associated with the training services; they were more confident, and they were willing to continue practicing the strategies within their home setting. Parents from the Baharav and Reiser ${ }^{11}$ investigation concluded that services delivered via telehealth at home were as valuable as sessions directly delivered by the clinician, but the authors reported that the parents expressed some dissatisfaction with the wireless headset and the need to stay within the range of the webcam, and they felt that the clinic room offered a more controlled environment. The majority of the parents from the Vismara et al ${ }^{4}$ study reported that they felt that the weekly videoconferencing sessions and the website video modules were the most helpful, and that the parents felt well supported by the program in spite of not having a therapist physically present in their home. Both studies reported that parents would recommend telehealth to other parents of children with autism.

\section{Limitations}

The authors of the studies discussed some limitations and challenges to the telehealth services that are important

Table 7 Averaged outcomes of parental skills on the P-ESDM

\begin{tabular}{llll}
\hline & $\begin{array}{l}\text { Data point I } \\
\text { (baseline) }\end{array}$ & $\begin{array}{l}\text { Data point 2 } \\
\text { (following } 7 \text { weeks } \\
\text { of intervention) }\end{array}$ & $\begin{array}{l}\text { Data point 3 } \\
\text { (follow-up) }\end{array}$ \\
\hline P-ESDM & $2.93(S D=0.60)$ & $3.68(S D=0.5 \mathrm{I})$ & $4.15(\mathrm{SD}=0.5 \mathrm{I})$ \\
\hline
\end{tabular}

Note: Data from Vismara et al. ${ }^{4}$

Abbreviations: P-ESDM, parent training program using the Early Start Denver Model; SD, standard deviation. 
to consider. Limitations and disadvantages were as follows: 1) difficulty with the use of the wireless headset; ${ }^{11}$ 2) staying in view of the webcam for the specialists' observations; ${ }^{11}$ and 3 ) time and expertise required to provide parental training for autism interventions. ${ }^{4}$ The last reported disadvantage, however, would be true for traditional intervention services as well. The disadvantages listed above are by no means insurmountable. The challenges identified were related to either the technology used to support and deliver the services, or the procedures used for observation and training. The continuously evolving and advancing technology will help address the challenges associated with wireless technology. Moreover, as more clinical research is conducted using these methodologies, guidelines for optimal viewing observations and parent-child activities will be determined. This is evidenced by the manner in which this second challenge was overcome in the Vismara et $\mathrm{al}^{4}$ study, where researchers reported that prior to the weekly intervention sessions, the therapist and parent strategized about different locations throughout the house where the laptop could be placed for optimal viewing of the parent-child activities and interactions.

\section{Discussion}

The evidence gathered from the two studies included in this review suggests that training and consultative services conducted via telehealth to parents with young children with ASD is feasible, effective, and equivalent to in-person services. Further review of the included studies yielded some advantages and disadvantages to telehealth services. Advantages discussed were as follows: 1) gains made in traditional therapy were maintained in the home environment; ${ }^{11}$ 2) minimally obtrusive services were provided by a highly trained professional within the home setting; ${ }^{11}$ 3) dissemination of the intervention was provided to families in need from remote locations; ${ }^{4} 4$ ) increased parental confidence was reported when training was delivered via telehealth methods; ${ }^{4,11}$ and 5) increased parental skills were observed following the online training. ${ }^{4,11}$

Limitations of this review include the sheer paucity of the studies found. Both studies reported using single-subject designs, which included a small number of participants. The two studies reviewed had an overall lack of standardized measures during recorded parent-child interactions, which made it difficult to assess how the results would generalize to other families. Due to these factors, the outcomes reported in these studies should be interpreted cautiously, and the generalization to the population at large may be limited.
The fact that only two studies met the inclusion criteria clearly indicates that there is a scarcity of evidence regarding the use of telehealth for the delivery of training programs for parents who have young children with autism. The limited amount of literature found may be due to the population assessed and the inclusion criteria utilized in this review. Although some children may exhibit early warning signs of autism spectrum disorder, they may not be diagnosed at an early age: ${ }^{15}$ therefore, studies that assessed the ability to train parents on the warning signs of autism rather than training on specific intervention strategies were not included in this review. Moreover, there were several published investigations that examined the use of distance education for parents with young children diagnosed with autism, but the program did not include any direct contact conducted through telehealth methodologies from a qualified professional. ${ }^{16-19}$ In those cases, the studies were excluded, as they did not meet the inclusion criteria.

\section{Future directions}

There is a paucity of investigations in the use of telehealth for training parents of children with ASD. Given the importance of parental involvement in the early development of their children, it is critically important that researchers continue to examine the effectiveness of training programs for parents using more robust research designs that include randomization and the use of control groups. Implementation of better-controlled designs would enable researchers to compare performance and outcome data of training/coaching rendered via telehealth, as compared to in-person training/coaching. Replication of the procedures cited in this review is necessary to further generalize the use and application of telehealth in this population. In addition, a greater range of parent-initiated intervention services delivered via telehealth should be examined with a focus on how these programs should be modified for a telehealth model. Further exploration is warranted with respect to the amount of support needed and the rate of learning demonstrated with a range of technology, equipment, and software by parents of young children with ASD. Finally, future research should examine the costs of a telehealth program, as compared to an equivalent on-site program. This information is critical in identifying the specific intervention and training procedures, policies, frameworks, and strategies that can be implemented to maximize development in young children with autism.

\section{Conclusion}

Telehealth has the potential to extend clinical outreach and provide services to families regardless of geographical location. ${ }^{18}$ 
The outcome of this review suggests that telehealth is an effective way to train parents of young children with ASD. This form of service delivery, when strategically implemented, has the potential to enhance the quality of services available to parents and caregivers who may be located in geographically remote areas, have scheduling conflicts and/or require additional material and resources. Given the advancements in technology and the growing need for EI services, it is anticipated that telehealth methodologies will be a mainstream form of service delivery in the future, which will make autism-specific services more readily available without compromising the quality of care delivered to families. It is clear that training parents and caregivers is key in helping children with ASD make progress toward the highest level of functionality, of which they are capable. ${ }^{11}$ Although further research is required to fully assess and understand the impact that telehealth training has on parental skill level and quality of care, the investigations summarized in this review provide the foundational evidence that may help improve the quality of training programs and procedures for parents who have a young child with ASD. This information, in combination with the technology advancements, supplementary equipment, and infrastructure of the Internet, will likely enhance the quality, quantity, and accessibility of training programs, and make a positive impact on the quality of life of families with young children diagnosed with autism.

\section{Disclosure}

The authors of this review are practicing clinicians providing telehealth services to children and families. They report no interest in the products or services presented in this paper. The authors report no conflicts of interest in this work.

\section{References}

1. American Speech-Language-Hearing Association [webpage on the Internet]. Guidelines for speech-language pathologists in diagnosis, assessment, and treatment of autism spectrum disorders across the life span. Rockville, MD: American Speech-Language-Hearing Association; 2006. Available from: http://www.asha.org/policy/GL2006-00049.htm. Accessed November 1, 2013.

2. Centers for Disease Control and Prevention [webpage on the Internet]. Austism spectrum disorders (ASDs) data and statistics. Atlanta, GA: Centers for Disease Control and Prevention; 2013. Available from: http://www.cdc. gov/ncbddd/autism/data.html. 2013. Accessed November 1, 2013.
3. Blumberg SJ, Bramlett MD, Kogan MD, Schieve LA, Jones JR, Lu MC Changes in prevalence of parent-reported autism spectrum disorder in school-aged US children: 2007 to 2011-2012. Natl Health Stat Report. 2013;65:1-11.

4. Vismara LA, McCormick C, Young GS, Nadhan A, Monlux K. Preliminary findings of a telehealth approach to parent training in autism. J Autism Dev Disord. 2013;43(12):2953-2969.

5. Strauss K, Vicari S, Valeri G, D'Elia L, Arima S, Fava L. Parent inclusion in Early Intensive Behavioral Intervention: the influence of parental stress, parent treatment fidelity and parent-mediated generalization of behavior targets on child outcomes. Res Dev Disabil. 2012;33(2):668-703.

6. Granpeesheh D, Dixon DR, Tarbox J, Kaplan AM, Wilke AE. The effects of age and treatment intensity on behavioral intervention outcomes for children with autism spectrum disorders. Res Autism Spectr Disord. 2009;3(4):1014-1022.

7. Handleman JS. Harris SL, editors. Preschool Education Programs for Children with Autism. Austin, TX: PRO-ED, Inc.; 2001.

8. Turner LM, Stone WL, Pozdol SL, Coonrod EE. Follow-up of children with autism spectrum disorders from age 2 to age 9. Autism. 2006;10(3): $243-265$.

9. Cason J. Telerehabilitation: an adjunct service delivery model for early intervention services. International Journal of Telerehabilitation. 2011;3(1):19-30.

10. Case-Smith J, Frolek Clark GJ, Schlabach TL. Systematic review of interventions used in occupational therapy to promote motor performance for children ages birth-5 years. Am J Occup Ther. 2013;67(4):413-424.

11. Baharav E, Reiser C. Using telepractice in parent training in early autism. Telemed J E Health. 2010;16(6):727-731.

12. Sparrow SS, Cicchetti DV, Balla DA. Vineland Adaptive Behavior Scales. Major psychological assessment instruments. 1989;2:199-231.

13. Dale PS, et al. MacArthur Communicative Development Inventories: User's guide and technical manual. San Diego, CA, USA: Singular Publishing Group, 1993.

14. Mahoney G, Powell A, Finger I. The maternal behavior rating scale. Topics Early Child Spec Educ. 1986;6:44-56.

15. Mandell DS, Novak MM, Zubritsky CD. Factors associated with age of diagnosis among children with autism spectrum disorders. Pediatrics. 2005;(116)6:1480-1486.

16. Kobak KA, Stone WL, Ousley OY, Swanson A. Web-based training in early autism screening: results from a pilot study. Telemed $J E$ Health. 2011;17(8):640-644.

17. Reischl U, Oberleitner R. Development of a telemedicine platform for the management of children with autism. German Journal for Young Researchers. 2009;1:22-29.

18. Symon JB. Expanding interventions for children with autism: parents as trainers. J Pos Behav Interven. 2005;7(3):159-173.

19. Wainer AL, Ingersoll BR. Disseminating ASD interventions: a pilot study of a distance learning program for parents and professionals. J Autism Dev Disord. 2013;43(1):11-24.

20. Smith M, Rogers S, Dawson G. The Early Start Denver Model: a comprehensive early intervention approach for toddlers with autism. Preschool Education Programs for Children With Autism, 3rd edition. Austin, TX, USA: Pro-Ed Corporation, Inc; 2008:65-101.
Smart Homecare Technology and TeleHealth

\section{Publish your work in this journal}

Smart Homecare Technology and TeleHealth is an international, peer-reviewed, open access online journal publishing original research, reviews, editorials and commentaries on the application of technology to support people and patients at home and in assisted living centers to optimize healthcare and management resources. Specific topics in the journal include: Development and application of

\section{Dovepress}

devices within the home and embedded in appliances; Healthcare provider communication and education tools; and drug ordering and adherence. The manuscript management system is completely online and includes a very quick and fair peer-review system, which is all easy to use. Visit http://www.dovepress.com/ testimonials.php to read real quotes from published authors. 